\title{
THE MUSIC OF THOMAS SIMAKU
}

Martin Scheuregger

ABSTRACT: The music of British-Albanian composer Thomas Simaku (b. 1958) bears the hallmarks of both his formative training and working life in Albania, and the widening of musical palette that came with his move to the UK in 1991. In this article the music from the late 1990s to the present day is considered, with particular attention to more recent works. An overview of some stylistic and technical aspects of this music is offered through analytical observations centred on three dualities: simplicity and complexity, the individual and the group, and stasis and movement. This wide-ranging account aims to open the door for further scholarship around this rich and multifaceted music.

Thomas Simaku leans in conspiratorially as if to tell me a secret; describing the piece he is about to start writing, his excitement is that of a child opening a long-awaited present. Talking to Thomas about music it is hard not to share this joy as he moves eagerly from telling me about the musicians he is working with to the residency he will take up later in the year. We are chatting over a drink at the University of York where Simaku works and where, as an undergraduate, I first came across his music. With colleague Tim Howell, Simaku supervised my hybrid music analysis/composition PhD from 2012, and across three more years I came to know his music in some detail. Returning to give a composition seminar in May 2019, I am pleased to find Thomas as excited about composition as he always was.

This excitement is as much about recent success as it is about the opportunities he has to simply write more music. 'I always feel proudest with my latest works,' he says in his recent interview with Frances Wilson ${ }^{1}$ : for Simaku the joy of composition seems only to increase with every new piece. As we sit discussing his recent performance at the ISCM World Music Days in Tallinn (May 2019) and his forthcoming CD releases

\footnotetext{
1 Frances Wilson, 'Meet the Artist - Thomas Simaku, composer', The Cross-Eyed Pianist (https://crosseyedpianist.com/2019/02/14/meet-the-artist-thomas-simaku-composer/, 2019).
} 
with Naxos and BIS, I tell him I have been studying his music for an article. Thomas is happy to share his thoughts and fill me in on his latest work, but he is equally intrigued to see what I make of it all. As a student of Simaku one gets to know how he thinks about music: structure is important, choosing the right notes is crucial, and without the right pacing a piece may fall apart. His preferred techniques for manipulating pitch collections, generating textures, and controlling harmony also stick in the mind. Returning to the department in which I studied, I reflect how much our formative surroundings shape the work we create, something that Simaku knows all too well.

Born in Kavajë, Albania in 1958, Simaku studied at the Tirana Conservatory from 1978 to 1982 where his composition teacher, Tonin Harapi, introduced him to music and ideas that set him on the path he would follow over the coming decades.

He didn't want his students to write the music that he wrote, so he 'let me free' to pursue my own interests - as free as one could be in a Stalinist regime where Stravinsky, among others, was in the government's bad books and was banned completely. But Debussy, Prokofiev and some Bartók (not the 'harsh' works of the middle period) were allowed, so I could listen to them, and managed to hear the 'Firebird' secretly! It was a strange feeling of awe and apprehension, created by the raw quality of the music of Firebird, and the fact that it was banned! I also liked the music of Feim Ibrahimi, who I felt was at the sharp end of the Albanian music of the time. I seem to have had an appetite for 'spicy' sounds in those days! ${ }^{2}$

Unable wholeheartedly to pursue the compositional approach he wanted to take or conjure the sounds he wanted to hear, Simaku sought new freedom, moving to England in 1991 to undertake a PhD in composition with David Blake at the University of York. Blake introduced him to the music of Bartók, Berio, Boulez, Stravinsky, Lutosławski and other twentieth-century figures but, in Simaku's own words, 'it was with the music of Ligeti and Kurtág that I felt I discovered something very special,

2 Frances Wilson, 'Meet the Artist - Thomas Simaku, composer', The Cross-Eyed Pianist (https://crosseyedpianist.com/2019/02/14/meet-the-artist-thomas-simaku-composer/, 2019). 
which was more than an inspiration to me. ${ }^{3}$ The impact of these last two composers - in pacing, textures, treatment of pitch and more - can still be felt in his music today.

The sense of discovery Simaku recalls at finding freedom, first by studying in a conservatoire, then in being introduced to decades of music previously unknown to him, seems to continue in his work now. Every piece opens a door onto a new world that seem to capture for him the same excitement that came with discovering the music of Ligeti and Kurtág for the first time. Works since the late 1990s demonstrate the maturing of Simaku's compositional voice and it is this period, and in particular recent works, that informs the broad introduction to his music here.

\section{Influences and themes}

Simaku's music bears the influence of the two geographical periods in his life and the two corresponding musical frames within which he worked at each time. Balkan particularly Southern Albanian - folk music was a fundamental early influence, with western modernism coming in to play after moving to the UK in 1991. Balkan influences very occasionally emerge in works which use overtly traditional material: Albanian Folk Song 'Moj a Bukara Moré' ('My Beautiful Morea') has been arranged in versions for many different instruments (published since 2015) ranging from soprano and piano to small ensembles, and sits alongside a number of other vocal works that wear their Albanian roots on their sleeves. But more common is for features of Simaku's musical heritage to emerge having been processed through an essentially modernist musical language. Critics have regularly commented on these qualities, including Colin Clarke's review of the 2008 Naxos release of two of Simaku's quartets and the first three of his Soliloquy cycle:

The intersection between individual contemporary utterance and regionspecific, folk-led expression is explored in all of the works here, but particularly in the quartets. Drones, microtones, heterophony and implied improvisation all inform his work. The influence of traditional musics is incorporated into his

\footnotetext{
3 Frances Wilson, 'Meet the Artist - Thomas Simaku, composer', The Cross-Eyed Pianist (https://crosseyedpianist.com/2019/02/14/meet-the-artist-thomas-simaku-composer/, 2019).
} 
expressive vocabulary - there is no use of direct quotation here. ${ }^{4}$

The composer himself is not coy about his Balkan influences, seeing his music as an attempt to 'focus on an idiom where ancient and modern aspects of utterance, musical or otherwise, interact and complement each other' as he '[puts] together elements from disparate musical cultures'. ${ }^{5}$ Although the result might suggest a more directly modernist influence, understanding the origins of Simaku's musical language - much of it owing to his time working with musicians in Southern Albania - makes greater sense of his stylistic traits. A more specific study of these influences is needed: here, only the generalised, essential characteristics of this music are observed.

The relationship to modernist music is more apparent, although it is more difficult to speak of influence here. The twentieth-century composers referenced above provide a stylistic and technical grounding through which Simaku has found his own modernist voice. Understanding the twin influences of traditional and radical musics leads to a better understanding of other dualities that are present in this work. Whilst not exhaustive, a set of concepts - each a pair containing inherent tension - provide a route in to rationalising this music: simplicity and complexity, the individual and the group, and stasis and movement. Furthermore, one can observe a fastidious attention to form, a predilection for heterophonic textures, and a tendency towards virtuosic writing. In attempting to better understand Simaku's music, these themes and concepts play a useful role and may inform future study.

\section{Simplicity and complexity}

The interplay between simplicity and complexity often relates to how material is presented and developed across the course of a work. Germinal ideas are usually simple, presented at the start and developed both locally and on a formal level, moving to more complex structures and textures as a piece progresses. Dense textures will

\footnotetext{
${ }^{4}$ Colin Clarke, 'Review: Voci Celesti (String Quartet No. 3); Due Sotto-Voci per Violino Solo; Soliloquy I (For Violin Solo); Soliloquy II (For Cello Solo); Soliloquy III (For Viola Solo); Radius (String Quartet No. 2) by Simaku, Kreutzer Quartet', TEMPO, Vol. 63, No. 249 (2009), pp. 98-99. 5 Frances Wilson, 'Meet the Artist - Thomas Simaku, composer', The Cross-Eyed Pianist (https://crosseyedpianist.com/2019/02/14/meet-the-artist-thomas-simaku-composer/, 2019).
} 
often be contrasted with simple material presented simultaneously in order to create vertical relationships between simplicity and complexity. Simaku speaks of 'a gesture or a motivic idea, which the listener can latch onto'6: it is often these ideas that are simple, with the challenge to the listener being to trace their development into more complex ideas and structures.

At its most complex, this music is characterised by the virtuosity which Simaku found both amongst folk musicians with whom he worked in Albania and in the modernist music which he was introduced to in the UK. This is a strong feature in his Soliloquy cycle, a series of solo works each of which represents a considerable technical challenge and a considerable compositional achievement. According to the composer, in these works 'a protagonist speaks in different languages... an actor play[s] different roles, where each character makes a considerable use of its own dialect'. ${ }^{7}$ The first three move through the strings: violin (Soliloquy I, 19988), cello (Soliloquy II, 2000) and viola (Soliloquy III, 2000); moving to woodwinds, Simaku turns first to the bass clarinet (Soliloquy IV, 2010), then to alto recorder (Soliloquy V - Flauto Acerbo, 2009) and to soprano saxophone (Soliloquy VI, 2013). There are still more to come, with a seventh on the cards for Ensemble Intercontemporain clarinettist Jérôme Comte, but it was the fifth work, for recorder player Christopher Orton, which landed Simaku a BASCA British Composer Award Winner in 2009 (solo/duo instrumental category). This work embodies the virtuosity characteristic of so much of the composer's music and, as the judges commented, it 'redefines the instrument in a visionary and entirely original way'. ${ }^{9}$

The virtuosity of Soliloquy $V$ leads to passages of relative musical complexity, but these build from simple germinal material. Here, as in many other works, this is presented in the gradually unfolding line of the opening (see Example 1). A single pitch

\footnotetext{
6 Frances Wilson, 'Meet the Artist - Thomas Simaku, composer', The Cross-Eyed Pianist (https://crosseyedpianist.com/2019/02/14/meet-the-artist-thomas-simaku-composer/, 2019). 7 Frances Wilson, 'Meet the Artist - Thomas Simaku, composer', The Cross-Eyed Pianist (https://crosseyedpianist.com/2019/02/14/meet-the-artist-thomas-simaku-composer/, 2019). 8 All dates are the year in which the work was completed as provided by the composer.

9 'Press release: BASCA announces 2009 British Composer Awards winners', at www.bbc.co.uk/radio3/newmusic/britishcomposerawards/2009/bcawinners.pdf, accessed 1 May 2019.
} 
(G) emerges from breath tones before a crescendo to the overblown top of the instrument's range sets the wide pitch space that the work moves on to fill. From here the $G$ acts as the tonic, interrupted first by accented grace notes and pitches which gradually pull the line further from its home note. Textural modifications and interruptions add increasing complexity to the line until a brief moment of rest on a Csharp (bar 11) shows that we have come, harmonically speaking, as far as we can. The return journey is much bumpier: greater prominence is given to the very highest range of the instrument, all notes are ether flutter-tongued or very rapid, and the fast passages that are to come later in the piece are pre-empted in the outburst which brings the music home to a $G$. When the music moves on it is, quite tellingly, the $G$ and C-sharp which form the first notes of the new line, compressing the moments of structural importance of the opening into a single rising gesture.

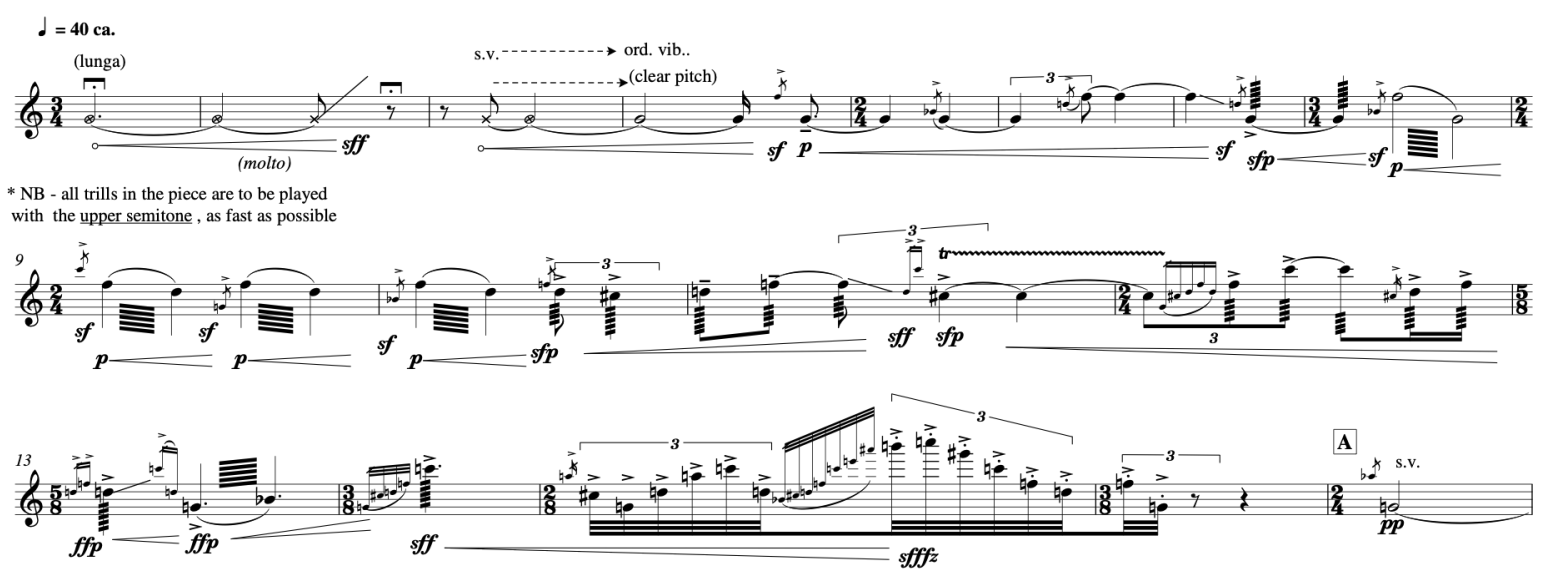

Example 1: Thomas Simaku, Soliloquy V - Flauto Acerbo (2009), opening passage (All music examples are printed with the kind permission of University of York Music Press.)

In the first minute of the piece, Simaku presents the basic harmonic and gestural building blocks with which the subsequent nine minutes will be created. A microcosm of the whole work, this opening still retains a sense of localised melodic and harmonic clarity: every pitch is sounded at only one octave, with a limited set (G, B-flat, C-sharp, $D, F, C$ ) maintained exclusively until the final gesture (bar 15) where some octave duplication occurs and further pitches are added. It would be going too far to ascribe this quasi-modality to a specific feature of Albanian music but its pitch centricity and 
limited pitch material certainly add to the sense that Simaku is synthesising elements of his musical heritage in this music.

The gradual unfolding of pitch material at the outset is common across many of Simaku's works. This is never a mechanical process, nor is it wholly intuitive, rather the rate and manner of unfolding appears to be a natural feature of the music, defining its character and mood from the outset. When deployed in ensemble pieces, the composer's predilection for heterophonic textures (present even more clearly in sections of micropolyphony) becomes apparent. In one of Simaku's most recent pieces, this technique is at its most chromatically restrained, resulting in music that casts a different stylistic light on the composer whilst maintaining a link to his essential approach. La Leggiadra Luna for mixed choir a cappella (2017) - a work selected for the ISCM World Music Days in 2019 - starts with the unfolding of apparently quintal harmony. Ds, Gs, then As are introduced and spread across the eight vocal parts. Grit is added to this harmony with the chromatic intrusion of a G-sharp a minor second below the $A$ but, whereas in another context a pearl of chromatic harmony might form around this, here the addition of F-sharp, $E$ and $B$ establish a brief $E$ major sonority before a return to the white-note harmony of the opening. The real pearl to which the whole work is aiming, however, is the eight-note chord that emerges in bar 54 (see Example 2). Objectively a tonal, albeit extended, chord, this moment is better understood as the ultimate result of the linear unfolding of increasingly detailed sonorities. It is also intervallically symmetrical and a chord which recurs in other of Simaku's work, as expanded below. Across the eight vocal parts, this is the densest chord that can be achieved and comes at the golden section of the piece ${ }^{10}$.

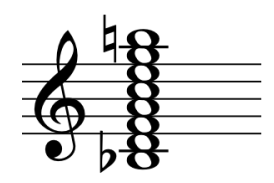

Example 2: Thomas Simaku, La Leggiadra Luna (2017), bar 54 chord

10 The golden section comes here or at the lunga pause that immediately follows this chord, depending whether one measures written beats or performed time, and is probably the result of deliberate formal planning. 
Rather than building harmony of increasing chromatic intensity, as in Soliloquy $V$ and in many other works, here carefully controlled linearity serves fundamentally harmonic contrasts between chromatic and diatonic elements which sustain the musical argument across the eight-minute work. Unusually for Simaku, the work tends towards a preference for the diatonic. Although at no point tonal in its treatment of pitch, $L a$ Leggiadra Luna does distinguish itself in the composer's oeuvre as a work which embraces material with overtly diatonic leanings. Whilst still employing a harmonic language characterised by chromatic complexity filtered through Balkan modality, Simaku demonstrates a different side to his work in pieces such as this, which although technically challenging for its performers is immediately engaging in its sonic simplicity.

The recent solo piano work L'image oubliée d'après Debussy (2018), directly quotes Debussay, as its title suggests. ${ }^{11}$ The diatonicism latent in La Leggiadra Luna is plain here thanks to the quotation. The language becomes increasingly chromatic as the piece progresses, but the simplicity of the opening quotation is maintained in a collection of somewhat stark chords arpeggiated "so that the "vertical" melodic lines, in both directions, up and down, are clearly delineated'12. These chords develop the opening not by moving towards complexity, but by recasting its simplicity in a chromatically-rich state. At moments across the work the diatonic material returns and the line between Debussy and Simaku becomes increasingly blurred. This is not simplistic music, but simplicity is certainly becoming a feature which the composer is not shy to embrace. Without being Kurtágian in its treatment of diatonicism and quotation, there is nevertheless something of Kurtág's unique use of simple material emerging in this music. The scope of Simaku's work may even be subtly changing: the chromaticism at its heart is unlikely to falter, but given that he is a composer who has already dealt with a substantial stylistic shift, a third period characterised by more restrained textures and harmonies may well be opening up.

\footnotetext{
11 This work was commissioned to mark the centenary of Debussy's death, and Simaku alongside other commissioned composers - was asked to begin the piece with a quote from one of Debussy's works before continuing in his own style.

12 Footnote in Thomas Simaku, L'image oubliée d'après Debussy (York: University of York Music Press, 2018), pp. 4.
} 


\section{The individual and the group}

The relationship between the individual and the group is played out in both the use of instruments and the manner in which compositional techniques are employed. In the micropolyphonic textures of large works such as the Concerto for Orchestra (2012) and The Scream (2016), individual instruments play independent, melodic parts whilst fundamentally functioning as the many layers of a collective texture. Virtuosic parts are given to instruments to serve both these textural functions (with multiple complex lines across an ensemble) and individual solo roles. Instruments occasionally separate themselves from the group altogether: at the end of Voci Celesti String Quartet No. 3 (2004) the first violin gradually leaves the other voices behind and ends the work playing solo at the very height of its range. In any number of instrumental works overtly virtuosic outbursts can be found. Even in solo works there can be individual/group interactions: Due Sotto-Voci per violone solo (2003) seems to contradict itself in the title, but works out this musical problem by 'taking in the violin both as a singer that sings in two voices, and as an orchestral body that accompanies itself. ${ }^{13}$ Indeed the substantial body of string music, in particular the string quartets, exemplifies tensions between the individual and the group.

The quartets - no. 1 (1991), no. 2 (2003), no.3 (2004), no. 4 (2011) and no. 5 (2015, commissioned by Huddersfield Contemporary Music Festival) - bear witness to Simaku's close work with the Kreutzer Quartet (to whom the second quartet, Radius, is dedicated) and Quatuor Diotima (the dedicatees of the fourth, and the quartet who premiered the fifth). This is a medium in which Simaku is completely at home: the first quartet was the first work he composed as a PhD student at York and he continues to teach a whole module on the form today. Through these works he finds ever new ways to manipulate the four voices of the ensemble, treating them in equal measure as separate soloists and as a singular canvas for timbral exploration. Virtuosity is never far away, and the range of approaches to colour, texture, harmony and line in these works point to much of what is important in Simaku's oeuvre. With a sixth quartet on

${ }^{13}$ Colin Clarke, 'Review: Voci Celesti (String Quartet No. 3); Due Sotto-Voci per Violino Solo; Soliloquy I (For Violin Solo); Soliloquy II (For Cello Solo); Soliloquy III (For Viola Solo); Radius (String Quartet No. 2) by Simaku, Kreutzer Quartet', TEMPO, Vol. 63, No. 249 (2009), pp. 98-99. 
the cards, the composer wishes, as he has said to me, 'to make it an "opus"!' and will no doubt explore these themes further.

The dynamic interaction of individual and group may be most readily achieved in a concerto, but when such a work has no named soloist - as is the case in Simaku's Concerto for Orchestra (2012) - such relationships manifest themselves in subtler ways. The manner in which individual instrumental voices contribute to the collective sound is crucial here. A triple-fortissimo chord across crotales, tubular bells, vibraphone and piano announces the the start of the work, subsiding to reveal the triple-piano chromatic cluster in the violins, played con sordino, sul tasto, senza vibrato. Coloured by the harmonically-rich bowed tam-tam and bowed cymbal notes, these opening seconds suggest a work all about gesture and colour, articulated through the careful combination of individual sonorities. When a solitary B-flat stopped horn note pricks the surface, this all changes. The note infests other parts of the orchestra as clarinet, flutes then brass gradually succumb, doubling this pitch. Despite the powerful gesture of the opening bar, the listener is left in little doubt that the piece will now follow the story of this one note, every other sound unravelling from it like an inevitable result of what has come before. The primacy of the line found in the Soliloquy cycle is once again present here. In Soliloquy $V$, however, where the character was that of the individual instrument, here the character is that of the collective. The myriad colours of the orchestra are not heard as individual voices, but as a single sonorous body carrying an expanding line: concerto this may be, but the literal symphonic quality (that of the orchestra 'sounding together') is unmistakeable.

As the work progresses, the notion of sounding together comes out in other ways. The orchestrated line of the opening becomes individualistic gestures at bar 41 as the vibraphone, marimba and harp play rhythmically active lines that stand out from the previously homogenous texture. Such soli groups coalesce at various points, with individual instruments also emerging (the staccatissimo bass clarinet part of bars 5354, for example). These stand in contrast to other material around them, but a fluid relationship between solo and ensemble roles leads to soloistic gestures becoming part of more singular textures when instrumental parts overlap with sufficient 
complexity (for example in the string parts from bar 106).

Although it is convenient to align the tension between the individual and the group with the form and genre of the work, this is a feature that is present across Simaku's entire output: soloistic and virtuosic writing for individuals within a group is something of a trope. A piece may innocently start with only or two notes, but it will often expand quite quickly into something more complex. When multiple instruments are involved, musical material is used both to bring instrumental sonorities together and to demarcate relationships between separate voices.

\section{Stasis and movement}

The musical arguments of the Concerto for Orchestra are established and worked out primarily through pitch. Pitch operates in two ways here: focal pitch centres demarcate the underlying structure, coming to the fore at moments of formal importance and pitch collections dictate the material between these formal pillars. Modal collections - such as that at the outset - are often found, with major and minor seconds highlighted in the melodic and harmonic intervals of the unfolding lines (such as that from bar 4). More complex non-tonal collections also appear frequently, as do moments of total chromaticism. The intervalic structuring of chords is similarly of importance: at one of the climactic points here, a chord - marked 'Hommage à Lutosławski' - is played prominently in the vibraphone. Made up of alternating minor and major thirds, this symmetrical harmony echoes harmonic construction elsewhere in this and other works, and is heard in transposition across the three striking wind, brass and percussion chords heard in the beginning of the Allegro Tumultuoso (from bar 106). The importance of intervals to Lutoslawski ${ }^{14}$ is reflected here and across much of Simaku's work; indeed the very same chord (in transposition) is heard at the climax of La Leggiadra Luna as noted above.

Apart from giving an indication as to the compositional strategies used, such an

${ }^{14}$ cf. Tadeusz Kaczyński, Conversations with Witold Lutoslawski, trans. Yolanta May (London: J. \& W. Chester/Edition Wilhelm Hansen London Ltd., 1984), pp. 38-40. 
approach suggests a composer for whom musical arguments are played out through linear and vertical intervalic relationships. In much of Simaku's work, individual pitches and static chords provide structural anchors, whilst linear movement between these points will often be defined through the use of carefully constructed interval patterns. A texture of complex overlapping instrumental parts can often be reduced to a pitch space defined by a single chord in which pitches are heard in only one octave (a technique reflecting the clarity found in Webern's Symphony, op. 21). This is heard in its most straightforward form in the opening bars of Soliloquy $V$ - Flauto Acerbo (see Example 1) and in denser harmonic passages in many other works.

The stasis of singular note or chords, juxtaposed with the more active motion of complex linear passages, typifies a strategy for development in Simaku's works. This tension between stasis and movement often relates to harmonic change and the techniques through which harmonic change is achieved. For Simaku, this feature has its origins in the heterophonic textures and drones of some Balkan musics, although a western resonance is found in the micropolyphony of Ligeti's Atmosphères (1961), Lux Aeterna (1966) and other works. In a central section of the Concerto for Orchestra (bars 135-169), contrasting static and active material types are heard simultaneously, demonstrating an approach to stasis and movement heard across Simaku's output. The previous section ends with a decisive F-sharp in octaves across much of the orchestra and as the Più mosso begins at bar 135, scurrying tremolo lines across a heavily divided string section propel the music forward. However, underneath this, the F-sharp is still heard, held across the violas before being passed to the celli (bar 141) and then back and forth between the two. As the section progresses, this pitch is everpresent, moving between string parts and occasionally bolstered with other instruments. Four strident, chromatically-rich chords punctuate the texture as it moves forward, but none manage to shake the persistently static F-sharp until, in a fifth and final accented chord (bar 169), it is eventually replaced by a prominent B-flat which goes on to take the role of the central pitch in the section that follows.

Across this section - a little over a minute of music - incredible momentum is achieved through rhythmic-unison string parts that propel the music as lines climb and fall. Each 
successive punctuating chord tries to shift the underlying material, but the everpresent F-sharp gives a static counterweight that prevents the music from formally progressing. There is a clear tension here between music that sounds full of movement but is formally static. In music which achieves its formal coherence through pitch centres, sections such as this (which achieve the move from one pedal point to the next) exhibit a tension between stasis and movement that is at the heart of what sustains the formal shaping and dramatic arcs of Simaku's works.

Elsewhere in the composer's oeuvre, localised static textures are used to generate formal scaffolding and provide space in which timbre can be explored. Most recently this can be heard in Klang Inventions (2018) - a piece echoing some of the gestural language of L'image oubliée d'après Debussy - where pitch centres and held harmonies feature prominently. The contrast between highly active sections and moments of stasis similarly articulates the structure of The Scream (2016), a work which unfolds slowly using frequent sections of harmonic stasis to explore the colour of the string orchestra. Here, even moments of great movement within parts can be understood as formally static. The closing bars (see Example 3) are a microcosm of this tension, contrasting a static held note with a highly active group gesture. Like the tension between the individual and the group, ideas related to stasis, movement and wider considerations of temporality provide great potential for understanding how this music operates and relates to broader issues in contemporary composition. 


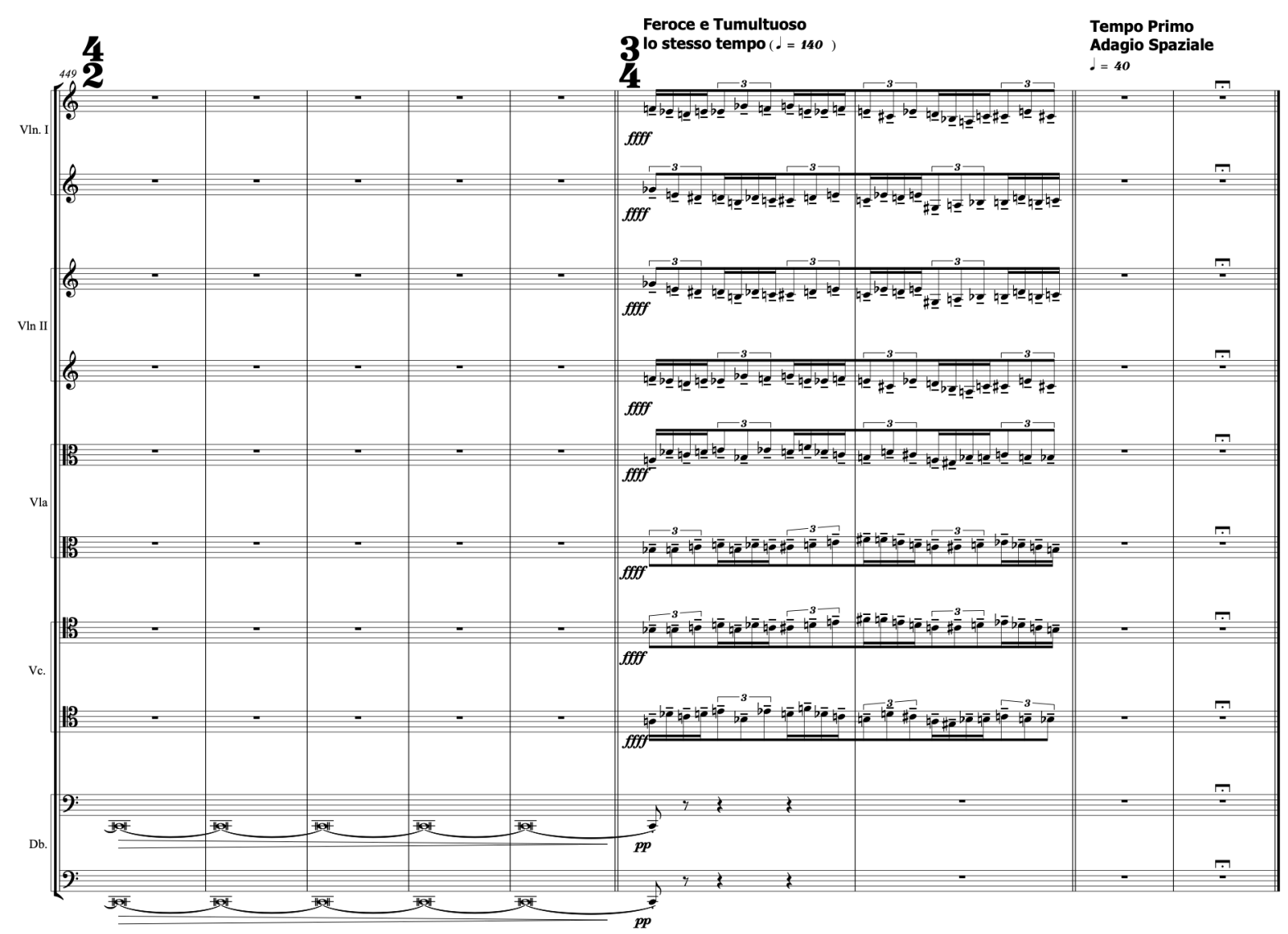

Example 3: Thomas Simaku, The Scream (2016), bars 449-457

\section{Conclusions}

In the space of this article it has been possible only to open up some of the issues inherent in the music of Thomas Simaku since the late 1990s. Some of these issues are evident from analysing this music and finding similarities of approach; others arise directly from the context of Balkan and then modernist musical influences which the composer himself is quick to point out. I have also touched on broader concepts that define the wider scope of Simaku's music and suggest the need for closer analytical study. In particular, notions of the individual and the group - which have been shown to have a bearing on a number of works here - might be expanded much further to understand the relationship between this music and that of other artists whose work has been influenced by a shift from a restrictive state to a more open one. The politics played out in this music needs further thought and, given the understated symbolism that occasionally crops up (police whistles appear several times and may not simply be there for sonic purposes) there is more to be said on this topic. Introducing The 
Scream on BBC Radio 3, the composer said that 'this piece is about human suffering and various levels of anxieties of our times'. The political and emotive content of this work can be explored more deeply.

The simplicity/complexity binary established here is perhaps a little crude but provides a useful shorthand for many features present throughout Simaku's music. By applying this binary frame, one can see the many ways in which the composer contrasts material both horizontally and vertically to affect gradual shifts, or abrupt changes that have structural significance. Musical material is built from the simplest elements often conceived in terms of intervalic relationships - which the composer uses to generate complex structures and harmonies and to inform virtuosic instrumental writing. The basic material of a work will deeply inform every element that follows, creating coherence - melodically, harmonically, structurally and in the relationship between instruments and/or voices - yet rarely giving away the direction of the work from the start. Finally, the idea of stasis and movement highlights approaches to texture whilst demonstrating the importance of pitch centres in the formal organisation of this music.

The music that Simaku wrote while he lived in Albania (before May 1991) has not been discussed at all here. Simaku's worklist from University of York Music Press (who publish the majority of his music) contains only his music from 1998 onwards and to understand the development of his style it will be important to investigate further these works from his earlier stylistic period. This music should be studied in detail and, more importantly, understood in the context of music from fellow Balkan composers working under censorship. Issues of musical narrative, latent in much of the discussion here, need further attention too and would no doubt be informed by a better understanding of Simaku's earlier work.

Simaku celebrated his sixtieth birthday in 2018 and is in his compositional prime. A mature and individual voice can be heard across his music and new directions may well still emerge. International performances and commissions of his music are increasing, so we are likely to hear even more music from this composer. Next time I 
sit down with Thomas in York I am sure I will find his excitement for composition still growing and I will listen with keen interest for how it may develop. 